\title{
NUEVOS TEXTOS SAPIENCIALES GRIEGOS EN OBRAS ÁRABE-CASTELLANAS
}

FRANCISCO R. ADRADOS

\begin{abstract}
A substantial part of Wisdom Literature texts translated to Castilian by the order of King Alfonso X come from Greek originals: that is certified by the Arab translators of Libro de los Buenos Proverbios (Hunayn) and Poridat de Poridades (ibn Batrik); and two other books, Bocados de Oro and Historia de la donzella Teodor, show the same characteristics. This paper is a first attempt to reconstruct, as fully as possible, the Greek models, as well as to trace their evolution from the 4 th century B.C. to the 7 th/8th A.D., when the books came to Arabs, directly or through Syriac translations. - Despite some Arab touch, these works are essentially the Greek texts of the Roman Imperial period, slightly modified by the Byzantine who added religious and palatine allusions, as well as Christian proverbs. Contents and form are coincident with the antique Wisdom Literature as far as we can know it, specially from the Lifes followed by collections of proverbs, and from the literature about Alexander the Great and Aristotle.
\end{abstract}

\section{El problema y nuestra respuesta al mismo}

Anticipando trabajos posteriores más detallados, voy a ocuparme de textos sapienciales castellanos traducidos del árabe (o reelaborados a partir del árabe) por iniciativa de Alfonso X el Sabio, a mediados delsiglo XIII: el Libro de los Buenos Proverbios, Poridat de Poridades, Bocados de Oro y La Historia de la donzella Teodor. Ahora bien, a diferencia de lo que sucede con otra traducción de la misma época del árabe al castellano, el Calila e Dimna, no conocemos el modelo de que proceden dichas versiones: a saber, según nos dicen los traductores, originales griegos. En cambio, para el Calila tenemos, ya que no una versión previa pehlví, sí modelos de ésta en sánscrito más o menos aproximados. Y para el Libro de los engaños e los asayamientos de las 
mujeres o Sendebar, traducido igualmente del árabe en las mismas fechas, podemos imaginar más o menos aproximadamente el modelo pehlví, derivado quizá de uno sánscrito anterior; aunque contiene claras adiciones de la tradición greco-romana ${ }^{1}$.

Pues bien, se trata en todos los casos de obras pertenecientes a la literatura sapiencial que llegó, desde varias fuentes, al mundo árabe; las Mil y Una Noches son un caso más. En el de las cuatro obras que mencionamos en primer lugar hay que partir del griego, traducido al árabe (en algún caso, parece, por el intermedio del siriaco). Lo que intento, aquí y en estudios que seguirán, es establecer que a partir de los textos castellanos (y de los árabes, por supuesto) son en cierta medida reconstruibles los modelos griegos, hoy perdidos.

Por ello, son completamente inexactas, en libros y artículos sobre la literatura castellana, las repetidas afirmaciones del "influjo árabe" u "oriental": es influjo griego, a través ciertamente de fuentes intermedias árabes; en otros casos, las fuentes intermedias son latinas. Otra cuestión es la de la fecha de los originales griegos: pienso que bizantina temprana, pero como culminación de una tradición antigua. Aunque no puede excluirse a priori algún retoque árabe (y siriaco, a veces lengua intermedia).

La existencia de traducciones árabes de textos griegos, científicos y filosóficos sobre todo, es bien conocida; y también que, en ciertos casos, solamente el texto árabe nos ha sido conservado. Este tema ha dado lugar a una amplia bibliografía a la que más adelante aludiremos. Pero esto se ha estudiado mucho menos para los textos sapienciales que para los científico-filosóficos. Lo que nos dicen los estudiosos de la literatura castellana (luego hablaré de esto) sobre esos orígenes es sumamente vago: evidentemente, es para ellos un tema lejano que les es poco familiar. Mayor interés ha despertado el tema entre unos pocos arabistas, aunque en general se han interesado más por las traducciones de textos científico-filosóficos, como acabo de decir ${ }^{2}$.

\footnotetext{
1 Sobre el Calila y el Sendebar véase mi Historia de la fábula greco-latina II, Madrid, 1985, p. 560 ss.

2 Por ejemplo, sobre las Vidas árabes de Aristóteles y sobre su doctrina, cf. autores como A. Baumstark, Aristoteles bei den Syren vom 5. bis 8. Jahrhundert, Aalem 1976 (reimpresión), p. 4 ss. y S. Pohl, «Die Aristotelische Ethik im Kitab al-Sa`ada wal-is`ad», en G. Kruk (ed.), The ancient tradition en Christian and Islamic Hellenism, Leiden 1997, p. 206 ss. Para el tema de la literatura sapiencial, incluidas las gnomologías, novelas de cartas y, en menor medida, alguno de nuestros tratados, daremos en un trabajo que seguirá a este la bibliografía oportuna: trabajos de Gutas, Strohmeier, Grignaschi, Rosenthal, Manzalaoui y otros. Y es notable la escasa atención
} 
Los argumentos a favor del origen estrictamente griego (no se trata de lejanas influencias convertidas en una nueva obra por los árabes) de los textos árabes traducidos al castellano son:

1. Los mismos autores árabes lo dicen. Así Hunayn, traductor (entre otras múltiples traducciones del griego) de Buenos Proverbios a partir de «libros antiguos», evidentemente griegos, pues dice a continuación que «los romanos (esto es, los griegos) fata oy en dia fazien sus libros e sus psalmos escriptos con oro y con plata en pargaminos tintos de la color que dixiemos» y sigue «falle escrito en unos libros de los griegos que un rrey fue en Grecia, etc.» ${ }^{3}$. El traductor de Poridat, Yahya ibn Batrik (Juan, hijo de Patricio), dice paralelamente que, encargado por el rey Miramamolín (el califa al-Ma'mon) de buscar este texto supuestamente aristotélico, lo halló (entre otros con letras de oro) en un templo de Homero el Mayor (Hermes Trismegisto), es decir, en un templo de la tarda antigüedad, y lo tradujo del lenguaje de los «gentiles» (del griego) al latín (al siriaco, véase más abajo) y de él al árabe ${ }^{4}$.

Nada dicen de sus originales ni al-Mubassir, autor de Bocados, ni el desconocido traductor de La donzella Teodor. Pero tampoco hablan ni el uno ni el otro de sí mismos, como los de las dos primeras obras. Parece que decir, por ejemplo, que Bocados utiliza «a Diógenes Laercio y otras fuentes tardías» ${ }^{5}$ o que la Donzella Teodor viene «del Oriente» ${ }^{6}$, es insuficiente, dada la conexión de ambos con géneros estrictamente griegos.

2. En la polémica sobre en qué medida textos árabes como estos, incluidos pseudoepígrafos como Poridad, sean traducción o recreación original, la opinión de los doctos se inclina cada vez más a la primera hipótesis. Nótese que no hay nada de musulmán en ellos y que proceden de un círculo no musulmán de Bagdad: el de cristianos nestorianos y jacobitas, principalmente.

3. Sobre todo, hay que insistir en la constante presencia en nuestros textos de los temas y los géneros literarios implicados en el universo cultural y literario griego.

Nos encontramos, efectivamente, con:

a estos textos árabe-castellanos en obras de tipo general como las de F. Rosenthal (citada arriba) y J. Vernet, La cultura hispanoárabe en Oriente y Occidente, Barcelona 1978.

3 Buenos Proverbios, ed. de H. Sturm, pp. 43 y 46. Ll. Kasten, «Poridat de Poridades», Romance Philology 5, 1951-52 estudia la relación con el Secretum Secretorum y no cree que las coincidencias de Buenos Proverbios con Poridat procedan de esta obra, sino de Hunayn.

4 Cf. Poridat, ed. Ll. A. Kasten, p. 31.

5 Ed. M. Crombach, p. XIII.

6 Ed. W. Mettmann, p. 77. 
a) Derivados más o menos lejanos de la leyenda de Alejandro, a distancia considerable, a veces, ya, del pseudo-Calístenes original, conservado en la recensión $a$; otras, más próximos a éste. A los datos derivados de las obras que comentamos, hay que añadir otros de obras árabes no traducidas al castellano: por ejemplo, fragmentos importantes de una novela en cartas que fue traducida al árabe, en opinión de Grignaschi, en época omeya ${ }^{7}$; y gnomologías árabes de origen griego pero que no siempre coinciden con las griegas que conservamos ${ }^{8}$.

b) El complejo de Vidas de sabios y filósofos griegos combinadas normalmente con una descripción fisiognómica y con series de máximas y de preguntas y respuestas entre un discípulo y el filósofo, todo ello en estrecho contacto con las Vidas y las gnomologías antiguas que nos han llegado. Y con distintas variantes: puede faltar la Vida, puede tratarse de máximas anónimas, etc. Esta libertad de combinación la encontramos ya en la tradición griega de época imperial. Y, en realidad, aparece desde los más antiguos gnomologios papiráceos sobre Sócrates y Diógenes, en el siglo IV a. C. ${ }^{9}$; y luego en Diógenes Laercio.

c) La variante consistente en el episodio en que alguien sale de una situación peligrosa contestando inteligentemente a una serie de preguntas del tipo ¿qué es...?, ¿qué es el más ...?, que incluye también enigmas; otras veces se trata tan solo de un certamen de sabiduría. La Vida de Esopo, la Vida de Secundo, el Banquete de los Siete Sabios de Plutarco y la Disputa de Hadriano y Epicteto son los ejemplos más conocidos, pero no, ni mucho menos, los únicos. Un eco importante se encuentra en Poridat (respuestas inteligentes de Aristóteles allí donde el hijo del rey fracasa) y, sobre todo, en La donzella Teodor, en que esta esclava triunfa en un debate de sabiduría sobre los sabios del reino. Este tema, de cuyo origen mesopotámico, en elAhikar, me he ocupado en otras ocasiones, encuentra ecos en el debate de Santa Catalina con los sabios e incluso, en el Evangelio, en el de Jesús con los doctores de la Ley.

Todo esto es claramente griego y, salvo excepciones referidas a Homero (en la Vida) o a Solón (en Heródoto), se centra, dentro de la filosofía que va de

7 Cf. M. Grignaschi, «Le roman épistolaire classique conservé dans la version arabe de Salim abu-1-'Alá», Le Museon 80, 1967, pp. 211-264.

8 Cf. D. Gutas, Greek Wisdom Literature in arabic translation. A study of the GraecoArabic Gnomologica, New Haven 1975; los «Sayings of the Ancients from Ibn Durayd's Kitab al-Mujtana», editados por F. Rosenthal en Orientalia 27, 1958, pp. 29-54; y G. Strohmaier, «Ethical sentences and anecdotes of Greek Philosophers in Arabic Tradition», en Actes du V Congrès d'Arabisants, en Correspondence d' Orient 11, 1971, pp. 436-471, entre otra bibliografía.

9 Cf. por ejemplo I. Gallo, Frammenti biografici da papiri, II, Roma 1980, p. 169 ss. 
Sócrates a Diógenes, en el complejo de literatura sapiencial que envuelve a Alejandro y Aristóteles (adscritos, en esa tradición, a la misma filosofía) y en algunos otros derivados del tema del debate de sabiduría.

Pero el tema de Aristóteles y Alejandro está ampliado en la literatura sapiencial por estratos tardíos, cristianos (citas de padres de la Iglesia de los siglos IV-V, referencias a Nuestro Señor y a la moral cristiana) y bizantinos (temas de la realeza y del ambiente cortesano). La verdad, entre la ética socrática, con sus múltiples desarrollos, y la cristiana hay múltiples coincidencias: nada extraño el sincretismo en que entraron. En las gnomologías bizantinas, que proceden de las antiguas y de Juan Damasceno, se unen máximas más o menos auténticas de la tradición que viene de Sócrates con otras de los padres de la Iglesia, como Basilio de Cesarea, Gregorio de Nazianzo y Juan Crisóstomo. En realidad, desarrollan los mismos temas del autodominio y autoexamen, el amor al pueblo, la obediencia a la naturaleza y a la ley divina, el aborrecimiento de la hybris y la pasión, el desprecio por el poder y el dinero. Son los mismos temas que hallamos en las máximas de nuestros tratados castellanos.

Ese sincretismo entre las doctrinas de los distintos representantes de las escuelas socráticas fue promovido fundamentalmente, en la época precristiana, por los cínicos ${ }^{10}$. Y esta línea se fundió con la cristiana: como digo, los padres de la Iglesia del siglo $\mathrm{V}$ fueron admitidos en las gnomologías al lado de Sócrates, Platón, Aristóteles, Diógenes, Esopo, Aristóteles, Plutarco, Galeno y los demás. Que a partir de un cierto momento, en Bizancio y en Siria, entraran temas cristianos en estas obras sapienciales, no es extraño.

Por supuesto, habrá que estudiar los diferentes estratos con más detalle. Pero, con frecuencia, elementos temáticos exactamente griegos, máximas, anécdotas y khreíai, por ejemplo, se conservan exactamente en los textos castellanos. Y en otras ocasiones habrá que concluir que otros elementos paralelos a aquéllos en cuanto a forma y contenido, son también griegos, aunque

\footnotetext{
10 Así D. Gutas, Greek Wisdom Literature in Arabic translation. A Study of the GraecoArabic Gnomologia, New Haven 1975, p. 453 ss. En esta obra y en bibliografía que cita sobre las gnomologías árabes no se pone en duda su carácter de traducciones del griego más o menos retocadas o modificadas; y estudia el tema detenidamente para la gnomología árabe que edita, el Siwān alhikmah o «La sala de la Sabiduría», de al-Sijistani, que ofrece grandes coincidencias con las demás, incluso las nuestras. Evidentemente, a los estudiosos de la literatura española se les ha escapado esta bibliografía.
} 
no se conserven literalmente en griego. Elementos árabes o musulmanes apenas existen; ni castellanos tampoco, salvo en el léxico de las instituciones. Como cuando en Poridat Alejandro hace a Aristóteles «su alguazil» o los filósofos se reúnen «en una eglesia»; o esta obra comienza hablando de «el rey mayor, el hondrado Dulcarnayn (nombre árabe de Alejandro, ya en el Corán)».

Los distintos sectores cronológicos e ideológicos griegos se combinan variamente, a veces de manera un tanto arbitraria, como cuando se mezcla la leyenda de Alejandro con la gnómica socrática y posterior. Y, como queda dicho, hay huellas claras de una evolución interna. Si todas estas acrecciones y combinaciones estaban ya en los modelos griegos exactos de las traducciones árabes de los siglos del IX al XI (e incluso anteriores, se piensa) o si una parte de ellas se deben a estos mismos traductores, sobre la base de materiales griegos hallados en la biblioteca de los califas de Bagdad, es el gran problema. De origen griego son en todo caso las más de ellas.

Aunque puede haber soluciones intermedias. Y aunque, sea cual sea la respuesta, queda pendiente el tema ya apuntado, merecedor de estudio, de cómo tuvo lugar el proceso de crecimiento de esta literatura desde la Grecia clásica a la bizantina.

Porque, como ya he anticipado, nos encontramos ante el concepto de literatura sapiencial, que es una literatura escrita en múltiples lenguas y con estructuras abiertas. Comprende fábulas, máximas, diálogos y debates, Vidas, anécdotas, temas eróticos y filosóficos varios (incluso novelescos), parodias, cartas, todo ello combinado variamente. Hay atribuciones cambiantes de los autores de las máximas y los protagonistas de las anécdotas y falsas atribuciones de cartas u obras: pseudoepígrafos, que decimos.

Esta literatura sapiencial la encontramos en Mesopotamia (desde los sumerios) y Egipto, luego en la Biblia, en Grecia en todas las épocas, también en la India y en Persia. De Grecia y la India (vía Persia) llegó una doble tradición al mundo árabe de Bagdad (luego de Egipto, etc.) y de aquí ya sabemos que a Castilla, luego a toda Europa. Pasó también a Siria (desde el griego o desde el árabe), a Armenia y Etiopía y a los pueblos eslavos. Pero también hay la tradición que va de Grecia a Occidente a través del latín. Nadie ha descrito nunca esta literatura sapiencial en su conjunto: es demasiado amplia, se incardina en demasiadas lenguas y culturas. Pero sus rasgos esenciales sí son conocidos. 
El tema de la transmisión es complejo. A veces la tradición indo-persa ha llegado a Grecia (caso del Barlaam); otras, la tradición griega ha pasado al latín (las varias colecciones de fábulas, la Vida de Alejandro de Julio Valerio, la de Secundo) o esto se supone, pero faltan los originales griegos (las obras de Dictis Cretense y Dares frigio, la Historia Apollonii regis Tyri, etc.); o bien hay creaciones latinas en la misma línea (colecciones de fábulas, la Altercatio Hadriani et Epicteti, etc.) Del latín imperial ha pasado toda esta literatura a la Edad Media europea. En nuestros manuscritos las obras procedentes de traducciones árabes y las procedentes de traducciones latinas se encuentran unas al lado de otras: se ha recobrado la unidad original.

Pues también sucede, y esto lo he propuesto en escritos míos anteriores, que cierta literatura sapiencial bizantina (de origen oriental o no) ha pasado a España a través de la Europa latina: así en el caso, por poner un ejemplo, de varias fábulas que están en ésta y en el Arcipreste de Hita ${ }^{11}$.

Aquí no hago sino una rápida referencia a cosas que son bien conocidas (aunque no todas lo son: no la línea Bizancio - Europa latina - España), con el fin de situar a nuestros textos dentro del ámbito literario al que pertenecen. El hecho es que a España llegó la descendencia de la literatura griega por dos vías: la de los árabes (que traían también la literatura de origen persa, a veces india en el origen) y la latina europea. Hay así un reencuentro de las diversas literaturas sapienciales: en nuestros manuscritos, como digo, conviven amigablemente obras de todas estas tradiciones, el concepto de literatura sapiencial, como un conjunto, continuaba vivo. Y España fue el punto de lanzamiento de todo este conjunto en dirección a la Europa latina y germánica. Aquí no hago sino explicar cómo una parte de la herencia árabe es, en definitiva, herencia griega.

$\mathrm{Ni}$ que decir tiene que yo he llegado a interesarme por este tema a partir de estudios míos sobre la literatura sapiencial, estudios que comenzaron por la fábula y cuyo principal exponente es mi Historia de la fábula greco-latina (1979-1987), ya aludida ${ }^{12}$. En esta obra y en varias posteriores, algunas citadas

11 Cf. por ejemplo mis trabajos «The earliest influences of Greek Fable on Medieval Latin writing», Classica et Mediaevalia 35, 1984, pp. 243-263.; y «Aportaciones al estudio de las fábulas del Arcipreste», en Philologica Hispaniensia in honorem M. Alvar, Madrid 1986, III, pp. 459-473. También Historia de la Fábula greco-latina cit., III, p. 511 ss.

12 Véase la traducción inglesa del vol. I, «History of the Graeco-Roman Fable», Leiden, 1999, puesta al día. 
más arriba (serán recogidas en un volumen que preparo, De Esopo al Lazarillo), tracé ya la historia, para la fábula y géneros conexos, de esos múltiples caminos, con España como punto de reencuentro. Y fui ampliando gradualmente el panorama para ocuparme, a más de la fábula, de las Vidas y debates, la anécdota y el cuento, la máxima, la literatura erótica y la novela.

\section{La literatura sapiencial y el concepto de tradición abierta.}

El concepto de tradición abierta lo aplicamos a los cuentos, anécdotas, romances, máximas, etc. para los que no es posible establecer un arquetipo del que derive toda la tradición posterior. Las discrepancias entre las diversas versiones no son «faltas», sino innovaciones de copistas, escritores o difusores orales que se creían autorizados a introducir una dosis de creatividad. O, inconscientemente, confundían o contaminaban.

Personalmente, he tratado este tema en detalle a propósito de la transmisión de la fábula y, también, del cuento erótico y la novela ${ }^{13}$. He puesto de relieve temas como el de los elementos griegos que entraron en el Calila y el Sendebar (aquí, sobre el precedente de Perry) en Bagdad, de la presencia de otros en la Haggadah, las Mil y Una Noches y Pedro Alfonso, la entrada de elementos orientales en las fábulas siriacas procedentes del griego, la combinación de las tradiciones oriental-bizantina y greco-bizantina en la fábula latina medieval, etc.

Creo que hay que recordar esto en nuestro contexto. Pues es cierto que la escuela de traductores de Bagdad, cuando hacía realmente traducciones de textos filosófico-científicos (filósofos, médicos, astrólogos, matemáticos, geógrafos, etc.) hacía exactamente eso: traducciones más o menos exactas.

13 Cf. por ejemplo «Desiderata en la investigación de la fábula antigua», en Actas del V Congreso Español de Estudios Clásicos, Madrid 1978, pp. 215-235; «Problemas de crítica textual en la transmisión de la fábula greco-latina», en La crítica textual y los textos clásicos, Murcia 1986, pp. 131-148; «Documentación suplementaria de la fábula greco-latina», Euphrosyne 18, 1990, pp. 213-226; «La fecha de la Augustana y la tradición fabulística griega y bizantina», Prometheus 18, 1992, pp. 139-149; «El cuento erótico, de los cínicos al final de la Edad Media», Argos 12, 1990-91 (1992), pp. 185-194; «Literatura sapiencial antigua en la Haggadah y Pedro Alfonso», Illinois Classical Studies 18, 1993, pp. 229-236; «La fábula en Bizancio, entre Grecia, Oriente y Occidente», Studi Italiani di Filologia Classica 11, 1993, pp. 195-204; El cuento erótico griego, latino e indio, Madrid 1994. Véase sobre todo mi Historia de la fábula greco-latina II, 1985 , p. 511 ss. («La fábula medieval griega y latina de tradición oriental e influjo de la fábula griega en Oriente»). 
Conocemos el método de traducción descrito por el hombre clave de la escuela de traductores de Bagdad, Hunayn ben Ishaq, que es comparable al de cualquier grupo de trabajo moderno y que podríamos llamar científico. Por supuesto, la tarea era difícil por motivos varios (manuscritos defectuosos, falta de conocimientos precisos sobre ciertos puntos) y no faltan los errores ${ }^{14}$.

Pero el traductor se consideraba simplemente eso: un traductor. El comentario o la interpretación quedaba a cargo de estudiosos posteriores: múltiples comentaristas y pensadores originales del tipo de Averroes y los demás.

En cambio, la literatura sapiencial no sabemos en qué medida era «traducida» y en qué medida era ampliada, reelaborada. Dado que estos procedimientos existían ya en Bizancio y existieron luego en Castilla, hemos de verlo, cuando no tenemos datos precisos es difícil establecer la parte que tomaron los árabes (y, a veces, antes los sirios) en esas reelaboraciones. La hubo importante, por ejemplo, en las Mil y Una Noches y en la leyenda de Alejandro, pero es más dudosa para nuestros textos. Aunque volveremos sobre el tema.

Por otra parte, el conocimiento de los más antiguos manuscritos árabes de nuestras obras dista, hoy por hoy, de ser completo; e incluso las más antiguas versiones castellanas deben, en cierta medida, reconstruirse ${ }^{15}$. El hecho es que las tres primeras obras que comentamos dan la impresión de que contienen abundantes contaminaciones y ampliaciones, mientras que la historia de la doncella Teodor (para la que, paradójicamente, no se nos habla del autor ni de sus fuentes) es de una estructura mucho más cerrada.

De todas maneras, algo podemos decir, aunque dejamos el detalle de las fuentes de las cuatro obras para estudios posteriores. De una parte, todo el ambiente de las obras lleva al mundo griego, cuyo estrato más reciente es el

14 Cf. sobre todo esto J. Vernet, ob. cit., p. 85 ss. Y, entre la múltiple bibliografía, varios trabajos en el libro de G. Endress (ed.), The ancient tradition in Christian and Islamic Hellenism, Leiden 1997. Pero, sobre todo, el libro de D. Gutas, Greek Thought, Arabic Culture. The GraecoArabic Translation Movement in Bagdad and Early Abbasid Society (8th-10th centuries), Londres-Nueva York 1998 (y mi reseña en Saber Leer 129, 1999). Más abajo adelanto algunas cosas.

15 Así la del Libro de los Buenos Proverbios, cf. J. T. Walsh, «Versiones peninsulares del Kitab adab al-falasifa de Hunayn ibn Ishaq», Al-Andalus 41, 1976, pp. 355-384. Para el texto árabe de Poridat hay un buen estudio de M. Manzalaoui, «The pseudo-Aristotelian Kitab Sirr al-Asrar», Oriens 23-24. 1974, pp. 147-247. 
bizantino: tema obsesivo, ya lo anticipé, del rey y su corte, sus palacios, esplendor y guerras, enseñanza en las diez artes; temas cristianos en las máximas (atribuidas a veces a los padres de la Iglesia de los siglos IV y V).

No hay, propiamente, un estrato musulmán. Sólo muy raras alusiones: sobre todo, al califa en los prólogos de las obras: se le nombra con su nombre propio, pero se le llama «rey». Las únicas referencias precisas son la de Buenos Proverbios, p. 55 de la edición de H. Sturm cuando dice que «los moros pintan en sus mezquitas», lo que apunta a la época omeya; y cuando cita a Locanen o Loginem (Lockman) en Buenos Proverbios, p. 50, Bocados, p. 146, pero en realidad es un equivalente de Esopo. Salvo, clara está, las referencias de «los prólogos externos» de Buenos Proverbios y Poridat, en que los traductores toman la palabra, hacen de narrador.

De todas maneras, hay que hacer constar que se ha propuesto ver una diferencia entre el proceder de Hunayn, en el siglo IX, y el de los autores del siglo XI, Ibn Sindi y al-Mubassir. El primero es un traductor, aunque ha podido unir fragmentos de una novela en cartas sobre Alejandro (que se piensa que fueron traducidas al siriaco y al árabe en la primera mitad del siglo VIII) y gnomologías; los segundos trabajan sobre textos árabes, ciertamente traducidos del griego ${ }^{16}$.

Hay ciertos indicios de modificaciones o variantes ya en los textos del siglo IX, pero no parece que alcanzaran el volumen de las variantes árabes y judías de la leyenda de Alejandro o de los múltiples agregados de las Mil y Una Noches. Tras precedentes siriacos, que pudieron introducir variantes, nos hallamos, en la corte de Bagdad del siglo IX, ante un círculo de cristianos (y adeptos al zoroastrismo) solo formalmente musulmanes. Y al-Ma'mon, el creador de la escuela, era un fanático de Aristóteles, que se le apareció en sueños. Todo transcurría al margen de la religión oficial. Con todo, algunas alteraciones o contaminaciones pudieron introducirse, algunos errores también, aunque creo que la mayor parte procede de Bizancio.

\footnotetext{
16 Así D. Gutas, ob. cit., p. 444 ss. Para el origen más temprano de las traducciones de la novela de Alejandro, cf. M. Grignaschi, «Le roman épistolaire classique conservé dans la version arabe de Salim Abu-l-Iskandar», Le Muséon 80, 1967, pp. 211-264; «LesRasa'il Aristatalisa ila-lIskandar de Salim Abu-1-Ala et l' activité culturelle à l' époque Omayyade», Bulletin d'Etudes Orientales 19, 1965-66, pp. 7-83.
} 
Hay alguna bibliografía arabista valiosa ${ }^{17}$. Pero muy poco dicen las obras más difundidas sobre la tradición de la Vida de Alejandro llegada a los modelos árabes de nuestras traducciones castellanas ${ }^{18}$. Y los helenistas (estudiosos del griego antiguo y del bizantino), evidentemente, apenas han puesto los ojos en ellas: porque no solo es que los autores de los textos árabes hablen de fuentes griegas, es que el contenido mismo muestra claramente ese origen. Cualquier helenista puede verlo ${ }^{19}$.

Es preciso, pues, un estudio independiente, apoyado ciertamente en la bibliografía arabista, incompleta pero existente.

Voy a presentar, pues, las líneas principales del problema: las características de nuestros cuatro textos, la literatura sapiencial griega en que se insertan y que los hace comprensibles, la fecha de llegada de los originales árabes a nuestra Península. Y hay dos cosas que querría recordar en primer término. Una, que hay que colocar las traducciones o reelaboraciones árabes de textos griegos a que me refiero en Bagdad, hacia la mitad del siglo IX d.C.: se trata, ya lo he dicho, de la escuela de traductores ya del griego, ya del pehlví fundada, sobre

17 Cf. por ejemplo J. Lippert, Studien auf dem Gebiete der griechisch-arabischen Uebersetzungliteratur. I. Quellenforschung zu den arabischen Aristotelesbiographien, Braunschweig, 1894; A. Baumstark, Syrisch-Arabische Biographien des Aristoteles, Leipzig, 1900; K. Merkle, Die Sittensprache der Philosophen, Kitab adab al falasifa, Leipzig, 1921; Aristoteles als Alexander's Lehrer in der Legende, Bonn 1966; F. E. Peters, Aristotle and the Arabs, New York University Press 1968; G. Strohmaier, «Ethical sentences and anecdotes of Greek Philosophers in Arabic tradition», en Actes du V Congrès d'Arabisants, en Correspondence d'Orient 11, 1971, pp. 436-471 y «Die arabische Sokrateslegende und ihre Ursprünge», Studia coptica (P. Nagel y J. Irmscher eds.); D. Gutas, Greek Wisdom in arabic translation: a study of the Graeco-Arabic Gnomologia, New Haven, Connecticut, 1975 y Greek Thought, Arab Culture, ya citado; G. Endress (ed.), The ancient tradition in Christian and Islamic Hellenism, Leiden 1997. Y lo que dice E. García Gómez en su amplia introducción a Un texto árabe occidental de la Leyenda de Alejandro, Madrid 1929.

18 Cf. G. Cary, The Medieval Alexander, London 1987, pero cf. p. 21 ss., 105, 146, 151; R. Merkelbach, Die Quellen des griechischen Alexandersromans, Munich 1954; E. García Gómez, Un texto árabe occidental de la leyenda de Alejandro, Madrid 1929. Son libros importantes, pero aportan poco a las variantes de nuestras obras. Recuerdo los dos trabajos de M. Grignaschi citados más arriba.

19 Nótese la escasa atención prestada a las traducciones de la literatura sapiencial en la obra más importante sobe la escuela de traductores de Bagdad en el siglo IX, la de Dimitri Gutas, Greek Thought, Arabic Culture, Londres 1998. Sobre las traducciones siriacas previas a las árabes, cf. por ej. A. Baumstark, ob. cit. (sobre Hunayn, p. 138 ss.). 
precedentes siriacos y, luego, de Al-Mansur y Harun al Rashid a fines del VIII, por el califa al-Ma'mon en el IX (Hunayn fue el principal traductor) y que se continuó luego en el X y sobre todo en el XI (al-Mubassir fue el traductor principal).

Claro que ya aludí a los precedentes siriacos y omeyas. Y que estos fechan las obras griegas en los siglos VII y anteriores: sin duda eran originales que se encontraban en Damasco y en el Oriente en general, pues en la época de los iconoclastas cesó la relación directa con Bizancio y la redacción allí de obras de este tipo.

Por supuesto que la traducción de obras científicas y filosóficas era lo esencial; pero no faltaban las obras sapienciales, procedentes igualmente ya del griego ya del pehlví; en uno y otro caso, a veces, a través del siriaco. De las características de estas sucesivas escuelas orientales de traductores he de decir algo, porque si no, no se entiende el tratamiento en las mismas de los textos griegos que aquí nos interesan.

Otra cuestión es la de llegada a Al-Andalus, en el lejano Occidente, de los textos árabes en cuestión, modelo de los castellanos. Sobre esto no se dice nada, en general: sólo que los originales árabes, tanto los científico-filosóficos como los sapienciales, fueron traducidos al castellano en la escuela de traductores de Toledo fundada en los años centrales del siglo XIII por Alfonso $\mathrm{X}$. Y que luego fueron imitados en la literatura castellana posterior. Esto es exacto, pero insuficiente.

Pues es claro que estos originales árabes fueron conocidos en Al-Andalus desde su origen en los siglos IX u XI, según los casos. Llegaron de Oriente: pues en Al-Andalus no hubo una escuela de traductores, se vivía de los libros que venían de Oriente, las traducciones del Bagdad abbasida. Baste con recordar lo que sabemos sobre la tradición del texto de Dioscórides, traducido en Bagdad al árabe en época abbasida (traducción de Esteban hijo de Basilio, revisada luego por Hunayn) y usada en España según cuenta el cordobés Ibn Yulyul. Pues bien, Romano, emperador de Bizancio, envió como regalo a Abderramán III en el año 948 un Dioscórides griego. Y resultó que en Córdoba nadie sabía griego, Abderramán hubo de pedir a Romano un traductor: como tal fue enviado un monje Nicolás, que se convirtió en una gran figura entre los 
médicos de Córdoba ${ }^{20}$.

\section{El «Libro de los Buenos Proverbios»}

El Libro de los Buenos Proverbios ${ }^{21}$ es conocido por dos manuscritos de El Escorial (L-III-2 y h-III-1, llamados L y H). Fue traducido por Hunayn ibn Ishaq, el personaje más importante del círculo de traductores de al-Ma`mon, nacido en 803 y muerto en 873 . Era un cristiano nestoriano que aprendió griego y siriaco en Asia Menor y fue llevado a Bagdad por el califa. Allí, rodeado de un verdadero equipo, tradujo innumerables obras filosófico-científicas (Hipócrates, Platón, Ptolomeo, Galeno, etc.).

Y tradujo, como acabo de decir, esta obra de literatura sapiencial. Describe el manuscrito original como un lujoso libro en pergamino con letras de oro y plata y que presentaba, en la página inicial, una imagen del filósofo sentado en una silla y rodeado de discípulos que aprenden. Era un manuscrito griego, ya dije: la traducción castellana habla de «los romanos» (es decir, rumís, griegos) y su prólogo afirma que Hunayn (a quien llama «Joaniçio, fijo de Ysaac») tradujo el libro del griego al árabe y «nos agora del aravigo al latín (esto es, castellano)».

Nótese que en ambos manuscritos la obra sigue a Poridat y está rodeada de otras obras sapienciales procedentes ya del árabe, ya del latín: formaban para el escritorio alfonsino un corpus unitario.

Narrada la obra por Joaniçio (aunque en un momento el narrador desaparece) existe la yuxtaposición bastante artificial de la anécdota de Anchos (derivada de la de las grullas de Ibico) y de un discurso moral centrado en torno a Aristóteles y dividido en dos partes: VI, VII, XIV - XVIII (tema Platón Alejandro - Aristóteles: enseñanza de Aristóteles, que culmina en una serie de máximas, luego vienen las cartas y los diálogos de Alejandro); y XIX-XXVI

\footnotetext{
20 Cf. J. Vernet, ob. cit., p. 69 ss.

21 Cf. H. Knust en Mitteilungen aus dem Eskurial, Tubinga, 1879, pp. 1-61; H. Sturm, The Libro de los buenos proverbios. A critical edition. Lexington, 1971; J. K. Walsh, «Versiones peninsulares del Kitab adab al falasifa», 1941, 1976, pp. 355-384. Sobre las colecciones aquí estudiadas y la prosa sapiencial castellana en general, cf. M ${ }^{\mathrm{a}} \mathrm{J}$. Lacarra y F. López Estrada, Orígenes de la prosa, Madrid 1993, pp. 31-43 y F. Gómez Redondo, Historia de la prosa medieval castellana. I, Madrid, 1998 (Poridat, pp. 273-286; Buenos proverbios, 440-455; Bocados, 455-463; Donzella Teodor, 282-502).
} 
(entierro y máximas de los filósofos, la corte y las mujeres, cartas consolatorias). Todo esto es coherente, pero se añade una serie de máximas de varios filósofos que ya van en comienzo (II), ya se intercalan (las de Sócrates, XII, y Platón, XIII), ya van al final a manera de apéndice (las de Diógenes, XXVII, y Pitágoras, XXVIII).

En total, nos hallamos no ante una Vida de Alejandro, sino ante un tratado moral acerca de su aprendizaje del gobierno y de su muerte, comentada por los filósofos, la madre y la corte. Es un tratado de gobierno y un tratado ascético. Todo esto ha atraído, sin duda, elementos morales ajenos que se han añadido bien en época bizantina, bien siriaca, bien árabe. Pero el carácter griego del núcleo y de los añadidos, es bien claro: únicamente, se trata de una estratificación de elementos ya helenísticos, ya de fecha imperial, ya posterior.

En el pseudo-Calístenes, aparte de la gran humanidad de Alejandro, hay escasos precedentes: la muerte por veneno, el sepulcro de oro (III 31) y otros. No es, ni mucho menos, la fuente única. Ni las enseñanzas, ni las cartas morales y consolatorias ni las reuniones de filósofos ni las gnomologías aparecen en él. Es, en suma, una obra completamente distinta, aunque sea en torno a la vida y muerte de Alejandro.

Parecen, a priori, elementos griegos la novela inicial entre Platón, Aristóteles y Alejandro, continuada por una serie de máximas de Aristóteles; la novela sobre la muerte de Alejandro, combinación de cartas y de plantos de filósofos; y otros más. Y también son griegas de origen las otras gnomologías, al comienzo y al final: pero parecen de origen independiente. Claro que estos elementos deben ser estudiados en detalle, contienen problemas de cronología y de posibles adiciones. Otra cosa es el ensamblaje de los dos niveles entre sí y con las demás gnomologías: puede ser griego o posterior. Y es árabe, desde luego, el prólogo exterior.

\section{4. «Poridat de Poridades»}

Nos hallamos, una vez más, ante una traducción al árabe en la Bagdad del siglo IX, esta vez por el cristiano sirio Yahya ben Batrik, Juan hijo de Patricio: traducida, ya dijimos, del griego al siriacoy del siriaco al árabe ${ }^{22}$. Este texto ha

\footnotetext{
22 Seguimos la edición de Ll. A. Kasten, Madrid, 1957. Véase también del mismo autor «Poridat de poridades», Romance Philology 5, 1951-52, pp. 180-190 (propone que hay acrecciones siriacas); F. Gómez Redondo, ob. cit., p. 273 ss.; y G. Cary, ob. cit., p. 21 s.
} 
llegado, en dos versiones: una más amplia u oriental (seguramente ampliada secundariamente), de la cual hubo una versión al latín de Filipo de Trípoli (Secretum secretorum) en el siglo XV (de ella vienen las versiones europeas, entre ellas una castellana del siglo XV); y una más reducida, de la cual, previamente a la versión castellana alfonsina, hubo una versión parcial al latín, obra de Johannes Hispalensis, y una hebrea obra de Al-Harizi, ambas del siglo XII.

Y una vez más nos hallamos, en realidad, ante una especie de espejo de príncipes o de reglas de gobierno organizadas en torno a la figura de Alejandro. Pero de él queda poco: tras el prólogo de ibn Batrik narrando la orden de búsqueda del rey y una introducción sobre Alejandro, viene el hallazgo del libro supuestamente de Aristóteles en un templo de Hermes Trismegisto y vienen siete tratados sobre el gobierno.

O sea, tenemos un prólogo exterior con la búsqueda y hallazgo del libro, algo que era habitual en esta literatura sapiencial árabe: en el Calila aparece lo mismo. Pero el prólogo admite la intercalación de un relato sobre Alejandro: sus grandes hazañas y su comportamiento humano después de recibir una carta de Aristóteles. Procedimiento no lejano del empleado por Hunayn. Ahora bien, la ficción consiste en que los siete tratados son parte de la carta, de cuando en cuando se comienza párrafo con un vocativo «Alexandre». Nos hallamos, pues, ante una carta que es, en realidad, un «espejo de príncipes» que continúa la tradición de Isócrates y, en realidad, una muy anterior que viene del antiguo Orie nte: la educación del príncipe por el filósofo. Solo que aquí hay una variante: el discípulo, Alejandro, se convierte en un verdadero filósofo. No hay, propiamente, máximas.

Todo es en torno al rey y la corte, con sus funcionarios, con una terminología medieval, tras el artificio de la búsqueda del libro y de la carta.

Es notable el prólogo inicial. Coincide, ya dije, con el Calila en el viaje para buscar el libro. Evidentemente, un prólogo de mítico o exótico ambiente era de rigor, se halla también en Buenos Proverbios y en la Donzella Teodor, también en precedentes orientales y griegos (Ahikar, Pañcatantra, Vida de Esopo, Banquete de los Siete Sabios, etc.) Lo notable aquí es el componente hermético, egipcio de origen como dice el libro, presente no sólo en el hallazgo

Recuérdese también el trabajo de M. Manzalaoui ya citado. Hay una edición del texto árabe de la recensión oriental de A. Badawi, El Cairo 1954. 
sino también en la petición de secreto. Podría discutirse si entró en fecha antigua, en Egipto, donde también se piensa que se escribió el pseudoCalístenes, o en época árabe, en que quedaban restos de hermetismo ${ }^{23}$.

Y también existen modelos antiguos de la relación Alejandro / Aristóteles, del recurso de las cartas, del uso de la falsa atribución a Aristóteles y de otros extremos. No puedo entrar aquí en el detalle.

\section{5. «Bocados de Oro»}

Esta obra ${ }^{24}$, otra traducción del árabe, es conocida por nueve manuscritos castellanos del siglo XV, a los cuales se añaden tres ediciones impresas de los siglos XV y XVI.

La traducción, datable en torno al 1048-49, es obra del médico y filósofo sirio al-Mubassir, que trabajó en la corte fatimida de El Cairo bajo el califa al-Zahir ${ }^{5}$ . A diferencia de las dos obras anteriores, el texto comienza abruptamente sin prólogo, esto es, sin indicaciones sobre el origen de la misma ni sobre el traductor; esta es la razón, pensamos, de que ciertos copistas se creyeran en el caso de añadir un prólogo según el cual el libro había sido traído de la India. Aparece, pues, como una gnomología pura y simple.

Todos los autores piensan que en ella se encuentran fuentes griegas: se habla de «escritos de la baja antigüedad tamizados ya por Diógenes Laercio» (Gómez Redondo, p. 455); Crombach, p. XIII habla de «fuentes» que en parte se han investigado para las máximas atribuidas a Zenón, Aristóteles, Alejandro. Véanse las obras de Endress, Lippert, Rosenthal y Strohmaier citadas ya. Pero no se trata de estudios sistemáticos ni para el detalle ni para los conjuntos gnomológicos referidos a los distintos autores antiguos: solo de algunas ideas generales. Más concretas son las coincidencias que D. Gutas, arriba citado,

23 Hay sentencias de Hermes en gnomologías árabes, cf. D. Gutas, ob. cit., pp. 45, 246, 309.

24 Seguimos la edición de M. Crombach, Bonn 1971 (tras la de H. Knust cit., p. 558 ss.). Cf. también M ${ }^{\mathrm{a}}$ J. Lacarra y F. López Estrada, Orígenes de la prosa, Madrid 1993, p. 33 y R. Gómez Redondo, ob. cit., p. 455 ss., donde se habla de la versión latina del s. XIII de Giovanni Procida (hay una fragmentaria, las máximas de Ptolomeo, anterior a la castellana), de las versiones amplificadas castellanas del s. XV, etc. Crombach, p. XIX ss. da noticia de las traducciones europeas dependientes de la latina.

25 El textoárabe fue editado por A. Badawi, Madrid 1958. Véase sobre él M. Crombach, ob. cit., p. XII ss. 
halla con varias gnomologías, sobre todo con la por él editada, una recensión de la de al-Sijistani.

La obra está organizada en una serie de capítulos que hablan de los dichos, a veces precedidos por los hechos, de una serie de personajes diversos, los más sabios griegos, pero a veces difíciles de reconocer.

La organización no es tan caótica como pudiera parecer. Hay que distinguir grupos:

1. Aparecen Hermes y tres personajes más incluidos en la leyenda Hermética. Es coincidencia notable conPoridat. Las gnomologías precedentes fueron adoptadas, evidentemente, por los círculos herméticos.

2. Capítulos referidos a sabios griegos que van de Homero a Galeno, en orden aproximadamente cronológico. Hay varias figuras enigmáticas y se incluye un cristiano (Gregorio) y un fabulista en que la tradición griega de Esopo ha penetrado en un antiguo personaje árabe (Loqman). En el caso de los personajes más importantes nos hallamos ante el complejo Vida (con fisiognomía) + máximas, en los demás sólo hay esta última parte (en Meadargis, fisiognomía y máximas). Este complejo Vida + máximas lo hallamos para Homero, Solón, Zenón, Hipócrates, Pitágoras, Sócrates, Platón, Aristóteles, Alejandro, Tolomeo y Galeno; y es especialmente amplio para la línea socrática de Sócrates a Alejandro, incluido aquí como sabio. Esto coincide con Buenos Proverbios. También, la gran extensión de las máximas de Diógenes (pero sin Vida). En suma, nos hallamos ante una orientación semejante a la de Buenos Proverbios, pero sin el eje biográfico de Alejandro (que allí, por lo demás, falla, como hemos visto) ${ }^{26}$.

3. Dos capítulos finales, recogidos evidentemente de las gnomologías: máximas de

26 A estos sabios griegos se añaden aquí y allá otros varios, algunos no identificados. Cito por las páginas de Crombach: 168 Proteus (Plutarco), Plinit (Apolonio de Tiana), Dimicratis (Demócrito, Demócrates o Demóstenes), Aseus (?), Asigranis (¿Arqui- ?), Escalibus (Asclepio); 169: Aracanus (?), Calides (¿Euclides?), Aplino (Filemón), Aseres (?); 170: Silus (Basilio), Tenparastis (Teofrasto), Abrachis (¿Hiparco?), Nichomatus (Nicómaco), Grenes (?); 170: Asajagonis (?), Polutucus (Plutarco), Quedaras (?), Domiciatis (Demócrito), Plimes (Píndaro); 172: Dicomes (?), Anicos (¿Anito?), Polos (¿Polo?), Ocason (?), Critus (Critón); 173: Amaron (?), Tisemus (?), Armesis (?), Milisius (Meliso), Pirgonos (Fedro); 184: Quedaris, Eugenius (Jenofonte), Ocriton (Critón), Eclimon (Filemón); 177: Vastacos (Pitaco), Bracalitos (Heráclito); 178: Ascidus (Hesíodo), Senus (Simónides), Acasagoras (Anaxágoras), Malisius (Meliso), Arsides (Eurípides); 178: Aderando (?), Aclines (?), Crianus (?), Quenis (?). Como se ve, junto a sabios griegos hay personajes de la leyenda hermética, otros de los Diálogos de Platón; y además Alejandro y Tolomeo, padres de la Iglesia, quizá algún persa. En la interpretación de estos nombres me ha ayudado la Dra. Conchita Gil Gangutia. 
autores poco fecundos en ellas y otras anónimas.

La tradición socrática, con su descendencia cínica y cristiana e incluyendo a Alejandro, domina: los temas son los mismos de la justicia, el autocontrol, los amigos, el buen callar, etc. Todo esto coincide con las otras obras que estudiamos y con la línea principal de las gnomologías griegas que conocemos en sus fases antigua y bizantina.

Naturalmente, el gran problema es el de si todo esto procede de las gnomologías antiguas y de qué fecha o si hay reelaboraciones; y el de la relación con las otras obras sapienciales de que nos ocupamos. Pero que nos hallamos ante una recopilación de gnomologías bizantinas tempranas, de origen antiguo y con fusión del cristianismo y de la doctrina hermética, es evidente. ¿Fueron ensambladas en la Antigüedad tardía o más tarde o la respuesta es mixta?

El problema grave, como ha visto Strohmaier, es el de si existen añadidos que pueden ser siriacos o árabes; él propone esto para una máxima socrática que se reencuentra en Bocados y en el mausoleo de una hermana de Tamerlán en Samarcanda. Y el de si la colección antigua pudo ser incrementada. Pues el esquema Vida + obra en la línea socrática es, sin duda, antiguo.

\section{6. «La donzella Teodor»}

Esta obra ${ }^{27}$ cierra el ciclo de las cuatro obras árabes derivadas del griego que fueron traducidas al castellano en nuestro siglo XIII. Se conservan en cinco manuscritos del s. XV (en varios como apéndice de Bocados) y en tres ediciones impresas del XV-XVI, entre cuyas versiones hay importantes variantes, recogidas en la edición de Mettmann. La historia fue muy popular en España: se hicieron numerosas ediciones y dio origen a un comedia de Lope de Vega, Historia de la donzella Teodor. Por otra parte, en este caso se conocen no una, sino varias fuentes árabes, también notablemente discrepantes entre sí.

Se trata del tema de la doncella, esclava además, que derrota a los sabios en un examen a que se somete. Narro primero sumariamente el tema de la obra castellana:

\footnotetext{
27 Edición de W. Mettman, La historia de la donzella Teodor, Mainz 1962. Cf. también M ${ }^{\text {a }}$ J. Lacarra y F. López Estrada, ob. cit., pp. 51 ss., y F. Gómez Redondo, ob. cit., p. 483 ss. También A. Wesselski, «Die gelehrten Sklavinnen des Islams und ihre Byzantinischen Vorbilder», Archiv Orientálni 9, 1937, pp. 353-378.
} 
Un mercader arruinado es aconsejado por su esclava Teodor que la venda al rey por diez mil doblas de oro: asegura que posee tal sabiduría en toda clase de ciencias y artes, que bien vale ese precio. La escena se desarrolla, según los manuscritos y ediciones, en Babilonia (referente a Babilonia de Egipto, sede donde luego se fundó El Cairo) o en Túnez; y el rey es llamado Abomelique Almançor o Miramamolín. Sigue la escena del examen ante un alfaquí «sabedor de justiçias e de leyes», un físico o médico y un poeta «sabidor de la gramática e de la lógica e de la buena fabla». Se trata de una serie de preguntas y de una serie de adivinanzas (¿qué es...?, ¿qué es la cosa más...?)

Los sabios son derrotados y el último ha de pagar a la doncella diez mil doblas para no verse obligado a despojarse de todas sus vestiduras, según había prometido. Y el rey pregunta a la doncella que le pida una merced: ella le contesta que la devuelva a su amo. Así lo hace él dándole diez mil ducados y enviándola a su amo ricamente vestida.

El relato tiene cierto ambiente cristiano: se menciona con frecuencia a Nuestro Señor Jesu Cristo, a la Virgen Santa María, etc., y en alguna versión Teodor es una esclava cristiana procedente de España. La acción se coloca en varias de ellas en Túnez, como se ha dicho.

Ahora bien, no hay duda de la descendencia a partir de versiones árabes varias, que aquí no puedo hacer sino indicar. Menciono sumariamente.

1. La de Las Mil y Una Noches, donde la historia de la esclava Twadduh es narrada por Sherezade entre las noches 436-462.

2. Una versión árabe castellana, en un manuscrito hoy en la Academia de la Historia, en Madrid.

3. Hay otro manuscrito árabe en la Escuela de Estudios Árabes de Granada, con variantes. Estas versiones árabes no responden exactamente a las versiones castellanas, aunque se aproximan más que la de Las Mil y Una Noches.

4. A. Wesselsky ${ }^{28}$ ha señalado la existencia de una versión persa, traducida del árabe.

5. Finalmente, Wesselski y Mettmann señalan una obra árabe, cuyo título se da en el Fihrist como «Libro del filósofo que fue examinado por la esclava Qitar y el relato del filósofo sobre este tema»: dice que es una traducción del griego.

Creo que, efectivamente, nos hallamos una vez más ante una tradición helénica, que esta vez aparece en versiones árabes y luego castellanas sometidas

28 Art. cit., p. 358 ss. ( y para la versión antigua de la esclava Qitar, p. 368 ss.). 
a procesos de reelaboración y añadido de variantes. Pero la bibliografía no precisa gran cosa, salvo hablarnos de las «doncellas sabias» en el caso de la Tarsiana de la Vida de Apolonio y de Sta Catalina, sometida a un examen ante los doctores; se añade el paralelo de la literatura de disputas, por ejemplo, la de Hadriano y Epicteto, y el de ciertas historias de monjas sabias en los Jataka indios ${ }^{29}$.

Todo esto es verdad, pero puede precisarse mucho más colocando la historia dentro del género mesopotámico (y luego indio, hebreo y griego) de las disputas en que un filósofo (o un esclavo o una doncella o un niño) se enfrentan a un poderoso (rey, amo, falso sabio, etc.) Siguen preguntas y adivinanzas en que el personaje pretendidamente inferior triunfa. salvándose del grave peligro en que se encontraba. Este género encontró máximo cultivo en la Antigüedad tardía. En términos generales me he ocupado de él en otros lugares ${ }^{30}$.

En suma: nos hallamos ante una versión más de la tan frecuente novela del personaje inferior en riesgo que se salva triunfando con su sabiduría frente a sus encumbrados oponentes. Pero mientras que en otras versiones, como la Vida de Esopo, el elemento novelesco domina, aquí, como en la Vida de Secundo y la Altercatio de Hadriano y Epicteto, es solo un marco o pretexto para la exposición de las ingeniosas respuestas, que son las más veces definiciones y soluciones de enigmas, de Teodor: nombre sin duda antiguo y recuperado por la versión castellana (Teodora se la llama en algunas versiones impresas). Algo parecido sucede en un texto complejo como es el Banquete de los Siete Sabios de Plutarco.

\section{Conclusión}

Con esto pongo fin a este esbozo de primeras conclusiones del estudio que estoy realizando. Podemos seguir en cierta medida la evolución de tradiciones biográficas, de «novelas de cartas», máximas de la tradición socrático-cínicocristiana, escritos de consolación, etc., a partir de fecha helenística y luego a

29 Cf. Gómez Redondo, p. 483; Mettmann, ob. cit., p. 76; Wesselski, ob. cit., p. 370 s.

30 Cf. mis «Elementos cínicos en las Vidas de Esopo y Secundo y en el Dialogo de Alejandro y los gimnosofistas», Homenaje a Eleuterio Elorduy, Bilbao 1978, p. 323 ss.; «The Life of Aesop and the Origins of Novel in Antiquity», Quaderni Urbinati, N. S. 1, 1979, p. 73 ss.; "Géneros helenísticos en el Banquete de los Siete Sabios de Plutarco», en Actas del IV Simposio Español sobre Plutarco, Madrid 1996, p. 130 ss. 
través de la imperial romana, para pasar a Bizancio y luego a Siria (a veces), a Bagdad y a Castilla. Son géneros sapienciales de origen oriental pero que en la Grecia helenística y posterior evolucionaron en torno a Vidas y episodios novelescos de Alejandro y de diversos filósofos, máximas de los filósofos, etc. El contenido y la forma nos son bien conocidos.

Solamente, no podemos precisar el detalle de la evolución ni las fechas de la misma. Fundamentalmente, es griega: antigua, imperial y bizantina. Los elementos posteriores son menores: más bien consisten en fusiones y ampliaciones.

Todo esto es importante, pienso, para la historia de la literatura y el pensamiento griegos, para el de su difusión en el mundo siriaco y árabe y luego en el castellano, después en toda Europa. Y es importante para que nos decidamos a definir la literatura castellana inicial, sobre todo la prosa, como una literatura de traducciones: de obras greco-árabes, perso-árabes y greco-castellanas, sobre todo. Nada hay de deshonroso en ello: así empezó la gran literatura latina y luego la armenia, la eslava, la germánica y otras más.

Por supuesto, la vía de entrada en Castilla estuvo en Al-Andalus, donde conocemos la presencia de estas obras, en ocasiones, en fecha anterior al siglo XIII en que fueron traducidas al castellano. Pero allí se trataba de obras importadas de Bagdad, fuera su origen griego o persa. También la literatura árabe fue, en sus orígenes orientales, una literatura de traducciones.

Insisto en que el tema de las fuentes griegas apenas ha sido tratado en la bibliografía de la literatura castellana, algo más (pero apenas para nuestras obras) en la de la árabe: he dado la bibliografía pertinente. El reciente libro de $\mathrm{M}^{\mathrm{a}} \mathrm{J}$. Lacarra, citado en nota 25, es paradigmático: de Buenos Proverbios dice (p. 49) que «la crítica parece pensar en una versión directa del árabe, sin prestar excesiva atención a las palabras del prólogo» (en las que Ioaniçio habla del original griego). Pues bien, claro que hay versión del árabe: pero ésta lo es a su vez de uno o varios originales griegos.

Sin entrar por el momento en esta difícil cuestión de la singularidad o pluralidad de los modelos, quiero insistir aquí en algunas cosas ya dichas. Por ejemplo: la Vida de Alejandro se convierte en un pretexto para escribir tratados morales e igual las gnomologías antiguas. Luego todo ello procede de tratamientos sucesivos en época imperial y bizantina, con pocas huellas de lo musulmán. Hay, efectivamente, un proceso de bizantinización y de cristianización 
de textos más antiguos, ya he presentado sus rasgos fundamentales.

Quiero insistir que este proceso no es único, ni mucho menos. Lo vemos, por ejemplo, en el Barlaam. Y también en la tradición del ps.-Calístenes: solo las recensiones bizantinas derivadas de la $\mathrm{B}$ (la E, la $l$, el $\mathrm{ms}$. L, la $g$, la $e$ ) presentan una serie de temas nuevos como la visita de Alejandro a Jerusalém o el cierre de los montes para bloquear el paso a los pueblos de Gog y Magog. Estas recensiones continuaron creciendo, igual que las colecciones de fábulas, hasta el siglo VII.

E igual sucede con las gnomologías de nuestras obras, que trabajan sobre otras cuyas citas remontan hasta el $\mathrm{s}$. V y luego fueron refundidas variamente. Aquí es donde mejor puede verse la estratificación: hay gnomologías de Sócrates (y de Diógenes) desde fines del s. IV a.C. ${ }^{31}$, contienen máximas o khreíai que vienen a veces de Jenofonte o Platón, otras entraron más recientemente y llegaron muchas de ellas a las gnomologías de Máximo Confesor y Antonio Melissa, en la Edad Bizantina, a través de otras intermedias. Surgen máximas nuevas o atribuciones a Sócrates de material cínico. Las gnomologías de Bocados y demás tienen este origen: pero a veces ofrecen material nuevo, casi siempre de origen griego, de cuya fecha de entrada dudamos. Este es un tema que hemos de estudiar. O sea: el tema de la tradición gnomológica greco-árabe debe ser estudiado aparte del de la novela o novelas de Alejandro y la novela de la doncella Teodor.

Nótese que el ambiente regio, los palacios y las joyas y, por supuesto, el ambiente cristiano, ha de atribuirse al mundo bizantino. Y errores groseros, como atribuir a unos autores máximas que no les corresponden o atribuir a Homero la fábula esópica de las dos alforjas (así Bocados), son propios de esta tradición. Así, ya en los gnomologios conservados en griego se dicen cosas tan erróneas como que Sócrates murió despeñado (así, en el Gnomologium Vaticanum 478). Desde el siglo IV a. C. al VII d. C. los gnomologios (y las colecciones de Vidas + máximas) fueron creciendo, casi siempre bajo influjo cínico, luego cristiano. Los bizantinos los aumentaron enormemente, cada vez con menos rigor: es fácil que sea suya, sobre base anterior, la mayor parte de las gnomologías de nuestras obras, aunque no puede excluirse alguna intervención árabe.

$\mathrm{Y}$ en todos los casos hemos de contar con redactores incultos, interesados

31 Cf. I. Gallo, Frammenti biografici da papiri, II, Roma 1980, p. 176 ss. 
por los temas de moral y no por el rigor histórico. Esto ya desde época helenística (fase antigua del ps.-Calístenes, de la Vida de Esopo, de las gnomologías) y luego cada vez más.

En suma, recogiendo cosas anteriores y añadiendo otras y prescindiendo por el momento del ensamblaje de los distintos elementos, hay una larga serie de estos que hay que atribuir a la primera época bizantina como coronamiento de estratos que vienen de la clásica. Añadidas a lo dicho más arriba, estas consideraciones hacen seguro que, si no en todos los casos las obras completas, sí al menos los elementos de que se componen son griegos. Griegos bizantinos, hasta el siglo VII. Pero son herederos, a su vez, de una tradición anterior que intento reconstruir.

Las dudas, la vacilación y, en definitiva, el casi silencio de muchos estudiosos de las literaturas árabe y castellana son injustificadas. Lo que dicen los traductores árabes es verdad: traducen del griego. Y los modelos griegos pueden ser comprendidos dentro de la tradición griega y pueden ser parcialmente redescubiertos. Porque a veces se han perdido en la tradición estrictamente griega. 